\title{
Distribuição da leishmaniose visceral canina na cidade de Presidente Prudente, Estado de São Paulo.
}

Distribution of canine visceral leishmaniasis in the city of Presidente Prudent, State of São Paulo.

Distribución de leishmaniasis visceral en perros en ciudad de Presidente Prudente, Estado de Sao Paulo.

Luiz Euribel Prestes Carneiro Professor do Mestrado em Meio Ambiente e Desenvolvimento Regional, Unoeste, Presidente Prudente, SP luiz@unoeste.br

Loris Aparecida Felício Daniel Aluna de mestrado de Meio Ambiente e Desenvolvimento Regional, Unoeste loris@unoeste.br

Francisco Assis da Silva, Professor Faculdade de Informática, Unoeste chico@unoeste.br 


\section{INTRODUÇÃO}

A leishmaniose visceral (LV) é uma zoonose emergente de grande importância para a saúde pública; sua distribuição geográfica é restrita a regiões tropicais e temperadas. Cerca de $90 \%$ dos indivíduos infectados com LV na América Latina estão no Brasil. O ciclo biológico é formado pelo mosquito Lutzomyia longipalpis (vetor) também conhecido como mosquito palha, pelo parasita Leishmânia chagasi, cão doméstico, considerado o principal reservatório e pelo homem, seu hospedeiro (1). No Brasil, a dispersão da LV está associada a diferentes fatores como clima, umidade, presença de conglomerados humanos, pobreza e a periferia das médias e grandes cidades. O ministério da saúde realiza diferentes ações como diagnóstico e tratamento precoce dos indivíduos infectados, identificação e eutanásia dos cães soropositivos, controle de vetores e educação da população. Apesar das medidas adotadas suspeita-se que a doença está se espalhando rapidamente em toda a região oeste do estado de São Paulo. A partir de 1997, quando o vetor L. longipalpis foi demonstrado no município de Araçatuba vizinha a região de Presidente Prudente, até 2014, 93,3\% dos casos de transmissão canina ou humana de LV em São Paulo ocorreu na região Oeste. Nela está a Rede Regional de Assistência a Saúde 11 (RRAS11), com sede em Presidente Prudente, reunindo 45 municípios entre eles o município de Dracena onde o vetor L. longipalpis foi detectado em 2003, e casos caninos e humanos da doença foram detectados desde 2005. Em Presidente Prudente o primeiro cão infectado foi diagnosticado em 2009 (2,3). Nosso objetivo é descrever a distribuição de cães diagnosticados com LVC na cidade de Presidente Prudente no período 2010-2015 e sua associação com a densidade populacional.

\section{MATERIAL E MÉTODOS}

Este é um estudo epidemiológico, descritivo seccional, tendo como local a cidade de Presidente Prudente, mostrando o inquérito sorológico realizado pelo Centro de Controle de Zoonoses (CCZ) para LVC entre janeiro de 2010 e dezembro de 2015. O município de Presidente Prudente, localizado nas coordenadas: latitude $22^{\circ} 07^{\prime} 32$ "S e longitude $51^{\circ} 23^{\prime} 20^{\prime \prime} \mathrm{W}$, de acordo com o censo do IBGE em 2012 tinha uma população de 207.725 habitantes dos quais 199.649 (96.1\%) estavam localizados na área urbana. Para geração dos dados, o perímetro urbano foi dividido em 7 micro regiões, com áreas de equivalência aproximada, tomando-se como base os setores censitários de 2012 do Instituo Brasileiro de Geografia e Estatística (IBGE). Foi determinado o número total de habitantes para cada micro região (figura 1).

\section{RESULTADOS E CONCLUSÃO}

No período estudado, 282 cães foram diagnosticados sendo 6 (2,1\%) em 2010; 32 (11,3\%) em 2011; 16 (5,7\%) em 2012; 27 (9,6\%) em 2013; 27 (9,6\%) em 2014 e 174 (61,7\%) em 2015. Não houve uma distribuição regular entre as diferentes micro regiões da cidade com um maior número de cães diagnosticados na micro região $2,91(32,2 \%)$ e um evidente aumento nas micro regiões contíguas 5 , $25(8,9 \%)$ dos cães e na micro região 6, 40 (14,1\%) dos cães, respectivamente. Em 2012 a população da cidade é de 199,649 habitantes, onde as micro regiões 2 possui 45,703 (22,9\%) habitantes; a micro região 3 com 55,098 (27,6\%) habitantes e a micro região 4 com 41,036 (20,5\%) habitantes 
(Figura1). Juntas as 3 micro regiões concentram $71 \%$ da população urbana. Exceto a micro região 2, nas demais regiões não houve uma relação entre o número de cães infectados e o número de habitantes.

Em todo o mundo, o cão doméstico representa um dos principais elos na manutenção do ciclo biológico da LV (1,3). Embora autoridades públicas tenham feito esforços para controlar o vetor e identificar a população canina na cidade de Presidente Prudente, o grande aumento do número de cães infectados em 2015 mostra a velocidade da dispersão da doença e isso parece não estar associado ao número de habitantes. Outros fatores de risco ambientais como presença de matas, córregos, animais domésticos, lixões clandestinos e áreas com matéria orgânica em decomposição podem estar associados a presença do vetor e a dispersão da doença.

Figura 1: Mapa da cidade de Presidente Prudente, região Oeste do estado de São Paulo com 7 micro regiões segundo os dados censitários do IBGE.

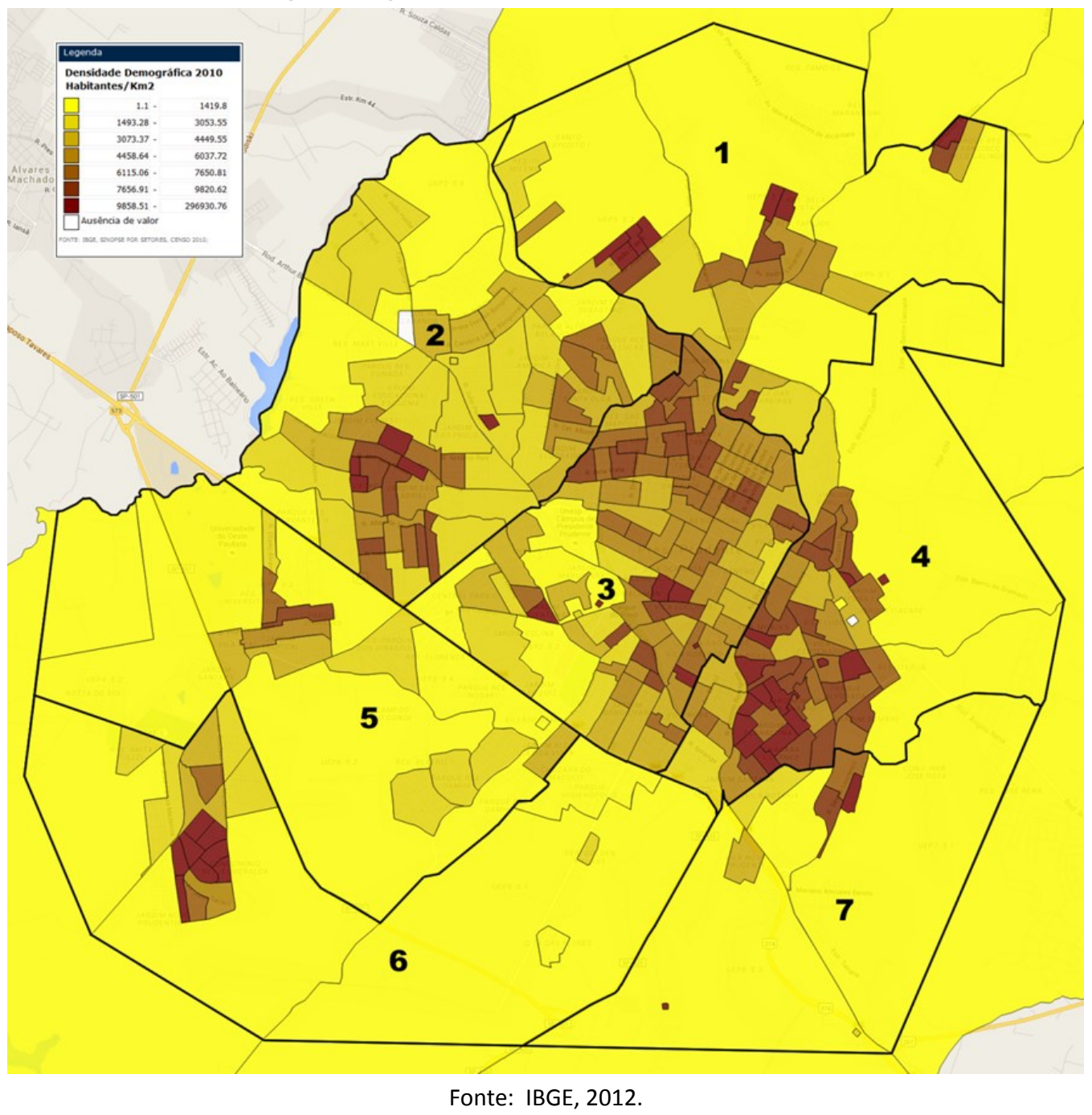

A densidade da população, da cor mais escura a mais clara, obedece os dados contidos na legenda. 


\section{REFERÊNCIAS BIBLIOGRÁFICAS}

(1)D'ANDREA, Lourdes Aparecida et al. The shadows of a ghost: a survey of canine leishmaniasis in Presidente Prudente and its spatial dispersion in the western region of São Paulo state, an emerging focus of visceral leishmaniasis in Brazil. BMC Vet Res. 2015 Oct 26;11:273.

(2)NAUFAL, Patricia Spir et al. Epidemiology of human immunodeficiency virus-visceral leishmaniasisco-infection. J Microbiol Immunol Infect. 2016 Apr;49(2):295-9.

(3)RIBEIRO, Vitor Márcio et al. Brasileish -A Study Group about Animal Leishmaniasis. Control of visceral leishmaniasis in Brazil: recommendations from Brasileish. Parasit Vectors. 2013 Jan $11 ; 6(1): 8$. 